\title{
The Well-Being of Junior High School Students in Taiwan in Relation to Familial Socioeconomic Status, School Life Adjustment, and Deviant Behavior
}

\author{
Hsiao-Fang Lin \\ Graduate Institute of Curriculum and Instruction, MingDao University, Changhua County, Taiwan \\ Email: goodly@mdu.edu.tw \\ Received October $14^{\text {th }}, 2012$; revised December $5^{\text {th }}, 2012$; accepted January $2^{\text {nd }}, 2013$
}

\begin{abstract}
This study explores the influence that familial socioeconomic status, school life adjustment, and deviant behavior have on the well-being of junior high school students. The participants were 1886 first-year junior high school students recruited using the Taiwan Education Panel Survey (TEPS). The findings of this study indicated that a) the well-being of male students exceeded that of female students; b) significant interaction effects were exhibited between familial socioeconomic status and school life adjustment, and higher familial socioeconomic status and higher school life adjustment with higher well-being; and c) deviant behavior was related to lower well-being.
\end{abstract}

Keywords: Familial Socioeconomic Status; School Life Adjustment; Deviant Behavior; Well-Being; Junior High School Students

\section{Introduction}

The issue of well-being has become a growing concern for people worldwide because everyone wants to have a happy life. The great Russian writer Leo Tolstoy once said, "To live happy, we should believe in the possibility of happiness". Thus, we may ask where the optimum place to be born is. In the "whereto-be-born index" published by the Economist magazine in 2013, Switzerland was ranked number one. Lyubomirsky, King, \& Diener (2005) stated that happiness can increase a person's quality of life and is the self-realization goal pursued by everyone. Regarding Leicester university psychologist, Adrian White, reported the first worldwide well-being map in 2006, he pointed out Denmark was the most pleasant and well-being nation among 178 nations and places which attended investigation. Finland was ranked 6th, the US was 23th, Taiwan was 68th, China was 92nd, Japan was 90th, and South Korea was 102. Previous studies have shown that the factors that most influence well-being are national health care, affluence, education, national identity, and homeland landscape aesthetics. The four Nordic countries of Denmark, Iceland, Finland, and Sweden are ranked among the highest primarily because of their excellent health care and education systems (Global Views Magazine, 2011). This demonstrates the significant influence that education has on well-being.

People generally believe that one's school days are the purest time of life, and that adolescence should be a period of carefree, happy growth. However, contemporary junior high school students in Taiwan commonly feel unhappy. According to data obtained from the 2010 Taiwan-Fukien Area Child and Youth Living Conditions Survey Report published by the Department of Statistics, Ministry of the Interior, Taiwan, approximately $62.8 \%$ of young people between 12 and 18 years of age considered schoolwork to be a bothersome problem. Regarding deviant behavior, approximately $30 \%$ had experience of cheating during an examination, with a relatively high $40 \%$ prevalence among juveniles from northern regions compared to those from other regions. Furthermore, approximately $25 \%$ had previously viewed pornographic material; $14 \%$ had truancy experience; $15 \%$ had beaten, kicked or used tools to harm classmates; and $50 \%$ admitted using swear words or foul language to insult classmates. However, the prevalence of these conditions declined as the parents' level of education increased. In addition, $12 \%$ of young people had been beaten, kicked, or hurt with tools by classmates, and approximately $40 \%$ had been sworn at or been insulted by their classmates using foul language (Taiwan's Ministry of the Interior, 2011). Junior high school students typically spend the majority of their time at school. Most of their interactions are with their teachers and peers. Thus, whether their relationships with teachers and peers are harmonious is often used as an index of perceived happiness (Wu \& Chang, 2003). Liu (2008) indicated that a correlation exists between school life adjustment and happiness, and that school life adjustment has a predictive effect for feelings of well-being. Adolescence is an important stage of personality development, and home and school are the most important life places during adolescence. Most previous research has examined issues related to depression. In recent years, positive psychology has become a popular field of psychology. In this study, we investigate the well-being of junior high school students in Taiwan in relation to familial socioeconomic status, school life adjustment, and deviant behavior.

\section{Background Literature}

\section{Familial Socioeconomic Status}

Paula and Andrew (2007) found that children in unstable families are typically prone to exhibiting behavioral problems, whereas children raised in stable two-parent families generally 
exhibit greater happiness because the behavior and attitudes of parents can affect the well-being of children. Socioeconomic status generally includes education, profession, and income as measurement indicators. These factors reflect one's position in the social hierarchy (Hwang, 2008). Coleman (1988, 1990) indicated that familial resources are present as three types of capital, that is, familial social capital, human capital, and financial capital. Familial social capital refers to the potential or actual resources produced through the interpersonal relationship interactions within the familial network. The head of the familial network generally holds the greatest human and financial capital. In other words, the head of a family typically has a higher level of education and income, which they pass to the next generation in the form of familial social capital (Werum, 2000). Lin (2001) also highlighted that because the socioeconomic statuses of families differ, inequality in familial social capital exists. Families with a higher socioeconomic status have greater financial capital and their children have greater access to educational resources, facilitating the attainment of greater educational accomplishments.

Students from families with a high socioeconomic status have a clear advantage in adjusting to school life compared to students from families with a low socioeconomic status. This is primarily because students from families with a high socioeconomic status have more cultural and financial capital. This capital not only influences the students' relationships with their teachers and peers, but also affects their school life adjustment (Wu \& Chang, 2003).

\section{School Life Adjustment}

Lazarus (1976) stated that "adjustment" refers to the responsive steps individuals take to survive in various environments or societies. These steps aim to enhance the psychological preservation of harmony between the individual and the environment. Lazarus also stated that adjustment is a responsive behavior executed by an individual to satisfy the demands of the environment. Adjustment can be employed to overcome internal pressure and enable an individual to maintain a harmonious relationship between their inner self and the external environment. Ladd (1989) reported that "school life adjustment" emphasizes the perceptions and attitudes children have toward school and their exhibited behavior at school, such as their attendance, participation in school activities, interactions with peers, and learning performance. Developmental psychologists contend that peers and friends have a significant influence on the development and adjustment of adolescents. Good interpersonal relationships increase the satisfaction adolescents have regarding school life and also improve their academic achievements (Epstein, 1983). Wu and Chang (2003) held that the meaning of "school life adjustment" included peer relationships, as well as the three items proposed by Ladd (1989). Lin (2000) argued that school life adjustment also includes the adjustment to studies, adjustment to conventions, and relationships with teachers and peers.

Adjustment to studies is the most important aspect of adjusting to school life and includes study habits, methods, and attitudes. Adjustment to conventions refers to the conditions and attitudes that students have toward following school conventions. Relationship with teachers refers to the quality of relationships between students and teachers, including interactions in class and the attitudes teachers have regarding students' study behaviors. Relationship with peers refers to the quality of relationships between students and classmates in typical joint study situations. Wentzel (1996) and Konu, Lintonen, and Autio (2002) held that when students and teachers have better relationships, overall well-being increases. In addition, Leung and Leung (1992) indicated that the relationship between parents and children is the optimum predictor of life satisfaction among young people. When parents' child-rearing methods are supportive or adopt a positive approach, they positively influence the life adjustment of school-aged children. When parents' child-rearing methods are overly controlling, parents negatively influence life adjustment (Lewis, 1995).

\section{Deviant Behavior}

Clinard and Meier (1992) defined deviant behavior as behavioral displays that violate social norms and value judgments set according to societal standards. In other words, the individual acts against the legal behavior or moral standards of the social system. So-called problem students in the school atmosphere are labeled "deviants" in the field of sociology. The behavior they exhibit is "deviant behavior," which often involves damaging school property and behavior that violates school rules and social norms (Liu, 2003). Adopting social control theory developed, Chiang (2003) emphasized that when an individual cannot maintain an appropriate relationship with society and other important institutions, such as the family, school, and peer groups, deviant or criminal behavior can potentially occur. Agnew and White (1992) indicated that one of the reasons deviant behavior is exhibited by adolescents is to alleviate feelings of insecurity and anxiety created by the gap between their anticipated and received achievements. Ollendick, Weist, Bordon, and Grace (1992) also indicated that if children lack positive peer relationships for a lengthy duration, they may engage in deviant behavior in the future. Academic accomplishments, teacher relationships, and peer relationships are the factors that influence the display of deviant behavior.

Students with exceptional academic achievements clearly engage in deviant behavior less frequently than that of students with a comparatively lower academic performance (Huang \& Lou, 2005). This is primarily because for students to attain a high academic performance, they must invest more energy in academic work; thus, they seldom interact with peers who engage in deviant behavior. In addition, their parents are typically more concerned with the discipline, education, and supervision of their children's lives. Consequently, deviant behavior is a rare occurrence. However, problems in school life adjustment may result from study conditions, teacher relationships, and peer relationships. When school life adjustment is poor, individuals can easily develop feelings of anxiety and insecurity. Individuals who lack appropriate ways to resolve these feelings are more likely to engage in deviant behavior as an escape or to vent their emotions. Maladjustment to school life may follow the manifestation of deviant behavior or, the display of deviant behavior may be an explicit behavioral response to the failure to adjust to school life.

\section{Well-Being}

In 2000, when serving as chairman of the Psychology Association, Seligamn proposed positive psychology theory (Seligamn \& Crikszentmihalyi, 2000). Well-being is among the 
focuses of positive psychology and emphasizes the overall evaluation of an individual's life. Andrews and Withey (1976) were the first psychologists to propose a complete definition for well-being. They contended that well-being comprises positive emotions, negative emotions, and life satisfaction. Diener (1984) proposed the following three main features of well-being: 1) Personal subjective feelings (Campbell, 1976), also known as subjective well-being (SWB); 2) possesses high positive emotions and low negative emotions; and 3) includes an overall evaluation of quality of life. Therefore, when people are satisfied with their overall life, their physical and mental health is enhanced, which increase their happiness. Brinkman (2002) believed that well-being is the result of the individual's overall self-evaluation of their quality of life. The level of well-being comes from the individual's acknowledged evaluation and interpretation of life. In other words, the level of satisfaction the individual has toward life is an indicator of their well-being. Diener (2000) held that emotional experience is the essential factor comprising subjective well-being. Emotional experience is divided into two aspects: positive emotions (such as joy, excitement, and satisfaction) and negative emotions (such as nervousness, depression, and anxiety). Cowley and Underwood (2002) discussed well-being from the perspective of physical and mental health, highlighting that people with superior physical health who are satisfied with their lives generally exhibit greater happiness. Freeman, Templer, and Hill (1999) held that a relationship exists between subjective health conditions and happiness. When a person's physical and mental health are both high, happiness is more easily felt.

Good life adjustment refers to an individual's perception that life thus far has been extremely satisfying overall. Thus, the level of satisfaction with life is a subjective indicator of wellbeing (Diener, 2000; Diener, Suh, Smith, \& Shao, 1995). Besides their home, junior high school students spend a significant proportion of their time at school. Li (2002) found that harmony in interpersonal relationships among adolescents is the most significant factor influencing perceptions of well-being. During studies at school, the quality of students' academic accomplishments and life adjustment is greatly influenced by their academic advisors (Lin \& Huang, 2008). Murray (2002) indicated that if teachers provide friendly support to students, students' life adjustment can improve and complications associated with negative emotions can be reduced. Numerous studies show that superior relationships between teachers and students can increase students' feelings of well-being (Wentzel, 1996; Konu, Lintonen, \& Autio, 2002).

The level of harmony in peer relationships is positively correlated with feelings of well-being (Noll et al., 1996). The degree of happiness felt by junior high school students is related to whether their relationships with peers and teachers are harmonious. Liu (2008) indicated that school life adjustment is intimately related to well-being. Healthy relationships between teachers, students, and peers increase one's well-being. Shyu (2007) showed that as deviant behavior declines among adolescents, feelings of happiness increase. Huang and Lou (2005) found that negative moods prompt the emergence of deviant behavior. Therefore, for individuals exhibiting significant behavior deviations, their sense of well-being is typically lower because deviant behavior and well-being exist in correlation. Summarizing these findings, this study investigates the relationships between Taiwanese junior high school students' familial socioeconomic status, school life adjustment, deviant behavior, and their well-being. From a gender perspective, McCulloch (1992) conducted a meta-analysis of a previous survey regarding well-being survey. He found that, because of the traditional orientation of gender roles, women were more sensitive to emotions, possessed greater emotional expression characteristics, and were more inclined to express a sense of positive well-being compared to men.

Reviewing relevant literature, we found that numerous studies and reports regarding the well-being of junior high school students have examined students' family socioeconomic status, school life adjustment, and deviant behavior. The issue of deviant behavior is a significant challenge when dealing with youth problems. Thus, in addition to deviant behavior and life adjustment issues, this study explores feelings of depression and criminal behavior from a positive psychology perspective to understand the current well-being of students in Taiwan.

\section{Methods}

\section{Participants}

Data examined in this study was obtained from the first wave of junior high school student questionnaires in the public version of the Taiwan Education Panel Survey (TEPS) (Chang, 2003). After removing invalid questionnaires, 1886 valid samples remained, comprising 875 questionnaires completed by male students $(47.39 \%)$ and 1011 questionnaires completed by female students $(53.61 \%)$.

The TEPS is a long-term tracking database established by Academia Sinica, the most prestigious academic institution in Taiwan. This database tracked one sample group, collecting first-year junior high school data in 2001, third-year junior high school data in 2003, first-year high school data in 2005, and third-year high school data in 2007. Many scholars in Taiwan continue to use this database for research because the information within this database possesses good reliability and validity. That the research data were collected a long time ago did not affect the study results.

\section{Measures}

The tools employed for this study were the responses to the junior high school student questionnaire and parent questionnaire from TEPS 2001. Following the TEPS database user manual instructions, we selected familial socioeconomic status, school life adjustment, behavior deviation, and well-being as the measurement variables for this study. Explanations of each variable are provided below.

\section{Familial Socioeconomic Status}

The fifth section of the parent questionnaire in TEPS 2001 concerns parental occupation. The answer options referenced the occupational categories established in the "New Occupational Prestige and Socioeconomic Scores for Taiwan", and were transformed into continuous variables using SPSS 18.0. Because the range of this scale was insufficient, we followed the recommendations of Hwang (2008) and employed the "Improved Version of New Occupational Prestige and Socioeconomic Scores for Taiwan". The resulting formula was "Improved Version of New Occupational Prestige and Socioeconomic Scores for Taiwan $=($ New Occupational Socioeconomic Scores-55) $\times 3$ ". Parents' occupational prestige scores 
were obtained after the conversion. The occupational prestige score achieved by fathers was combined with that achieved by mothers, and the average value was used to determine the familial socioeconomic status. The samples were then divided into three groups according to their socioeconomic status scores; scores ranging from 81 to 94 were categorized as high socioeconomic status, scores ranging from 76 to 80 were categorized as average socioeconomic status, and scores ranging from 35 to 75 were categorized as low socioeconomic status.

\section{School Life Adjustment}

Seven items were selected for "school life" from the third section of the junior high school student questionnaire, and six items were selected for "about me" from the fifth section, for a total of 13 items, which were used as school life adjustment measurement variables. Exploratory factor analysis and varimax rotation were used to extract the following three factors: study adjustment, peer relationships, and student-teacher relationships. The extraction sums of the squared loadings were $23.05 \%, 15.23 \%$, and $12.76 \%$. The cumulative extraction sum of squared loadings was $51.04 \%$, and Cronbach's $\alpha$ value was .83. Subsequently, the "learning adjustment" and "peer relationship" factors were subjected to reverse scoring. The higher score the better the school life adjustment. The samples were divided into three groups from high to low according to their school life adjustment scores; scores ranging from 40 to 52 were categorized as high school life adjustment, scores ranging from 35 to 39 were categorized as ordinary school life adjustment, and scores ranging from 14 to 34 were categorized as low school life adjustment.

\section{Behavior Deviation}

Using the definition of behavior deviation provided by $\mathrm{Wu}$ (1978), seven items were selected for "about me" from the fifth section of the junior high school student questionnaire. A four-point Likert scale was used for scoring, with 1 denoting "never," 2 denoting "sometimes," 3 denoting "often," and 4 denoting "usually." Higher scores indicated more serious displays of deviant behavior. In other words, the higher score, the more serious the deviant behavior. Using exploratory factor analysis and varimax rotation, an eigenvalue of 3.62 was obtained. The factor loading of each measurement variable was greater than .5 , the cumulative extraction sums of squared loading was $51.66 \%$, and Cronbach's $\alpha$ was .75 . The samples were divided into two groups according to their deviant behavior scores; scores ranging from 11 to 21 were categorized as high deviant behavior, and scores ranging from 1 to 10 were categorized as low deviant behavior.

\section{Well-Being}

Four items were selected for "school life" from the third section of the junior high school student questionnaire, and 10 items were selected for "about me" from the fifth section, for a total of 14 items, which were used as well-being measurement variables. A four-point Likert scale was used to score the participants' responses regarding "emotional reaction" and "physical health," with 1 denoting "never," 2 denoting "sometimes," 3 denoting "often," and 4 denoting "usually".

Self-satisfaction was scored using a three-point scale, with 1 denoting "not at all satisfied," 2 denoting "somewhat satisfied," and 3 denoting "mostly satisfied". Exploratory factor analysis and varimax rotation were used to extract three factors, namely, "emotional reaction," "self-satisfaction", and "physical health." The extraction sums of squared loading were $24.95 \%, 15.24 \%$, and $13.35 \%$. The cumulative extraction sum of squared loading was $53.54 \%$, and Cronbach's $\alpha$ was .88. Higher scores indicated superior well-being.

\section{Results}

\section{The Influence of Gender on Well-Being}

Comparing emotional reactions, self-satisfaction, and feelings of physical health between the male and female students, Table 1 shows that regarding emotional reaction, male students exhibited superior emotional reactions compared to female students $(t=7.64, p<.001)$. Regarding self-satisfaction, male and female students showed no discrepancies $(t=.84, p>.05)$. Regarding physical health, male and female students also showed no discrepancies $(t=1.63, p>.05)$. Regarding wellbeing, male students exhibited higher well-being compared to female students $(t=6.07, p>.001)$. Considering the effect size, the value of $\eta^{2}=.03(<.06)$ for emotional reaction indicated a weak relationship. Gender also showed a weak correlation with well-being $\left(\eta^{2}=.005\right)$. These results suggest that a minimal correlation exists between gender and well-being.

\section{Two-Way Analysis of Variance (ANOVA) for Familial Socioeconomic Status and School Life Adjustment in Relation to Junior High School Students' Well-Being}

A two-way ANOVA comparing family socioeconomic status and school life adjustment in relation to junior high school students' well-being showed a significant difference, with (familial socioeconomic status * school life adjustment) achieving an $F=10.664$ and $p=.000$. This shows that both familial socioeconomic status and school life adjustment significantly influence well-being. Thus, a simple main effect test was performed for further analysis, as shown in Table 2.

The following findings have been inferred based on the results shown in Table 2:

1) Regardless of the level of school life adjustment, students from families with a high socioeconomic status exhibit the highest level of well-being, followed by those from families with a moderate socioeconomic status and a low socioeconomic status.

2) In families with a high and moderate socioeconomic status, junior high school students with a good and moderate school life adjustment exhibited higher levels of well-being compared to students with poor school life adjustment. No significant difference was observed between students with good and moderate school life adjustment.

3) In families with a low socioeconomic status, students

Table 1.

Summary of the $t$-test results for each dimension of well-being.

\begin{tabular}{llll}
\hline Factor & $t$ & $\eta^{2}$ & Notes \\
\hline Emotional reaction & $7.64^{* * *}$ & .03 & Male $>$ female \\
Self-satisfaction & .84 & - & \\
Physical health & 1.63 & - & \\
Well-being & $6.07^{* * *}$ & .005 & Male $>$ female \\
\hline
\end{tabular}

Note: ${ }^{* * *} p<.001$. 
Table 2.

Summary of the results of a simple main effect test on the ANOVA results for familial socioeconomic status and school life adjustment in relation to junior high school students' well-being.

\begin{tabular}{llllll}
\hline Source & SS & df & MS & $F$ & post hoc \\
\hline A factor (familial socioeconomic status) at & & & & & \\
b1 (High) & 2506.728 & 2 & 1253.364 & $282.386^{* * *}$ & high $>$ middle $>$ low \\
b2 (Middle) & 1382.793 & 2 & 691.397 & $120.992^{* * *}$ & high $>$ middle $>$ low \\
b3 (Low) & 2729.282 & 2 & 1364.641 & $58.466^{* * *}$ & high $>$ middle $>$ low \\
B factor (school life adjustment) at & & & & & \\
a1 (High) & 6377.500 & 2 & 3188.750 & $170.137^{* * *}$ & high $>$ low; middle $>$ low \\
a2 (Middle) & 2551.133 & 2 & 1275.566 & $187.981^{* * *}$ & high $>$ low; middle $>$ low \\
a3 (Low) & 2402.310 & 2 & 1201.155 & $164.020^{* * *}$ & high $>$ middle $>$ low \\
\hline
\end{tabular}

Note: ${ }^{* * *} p<.001$.

with good school life adjustment exhibit the highest levels of well-being, followed by students with moderate school life adjustment and students with poor school life adjustment.

\section{Two-Way ANOVA of Familial Socioeconomic Status and Behavioral Deviation in Relation to Junior High School Students' Well-Being}

The results of a two-way ANOVA comparing familial socioeconomic status and behavioral deviation in relation to junior high school students' well-being did not show significant differences, with (familial socioeconomic status $*$ behavior deviation) achieving an $F=.376$ and $p=.687$. Thus, we can infer that the combined effect of familial socioeconomic status and behavioral deviance does not have a significant influence on well-being. However, a significant difference exists between familial socioeconomic status and well-being. A main effect test on the results of a one-way ANOVA with $F=968.71$ and $p$ $<.001$ indicated that students' overall well-being differs significantly according to familial socioeconomic status. The overall well-being of Taiwanese junior high school students is higher for students from families with a high socioeconomic status compared to those with a moderate socioeconomic status; students from families with a moderate socioeconomic status also showed higher levels of well-being compared to those from families with a low socioeconomic status.

\section{Two-Way ANOVA of School Life Adjustment and Behavioral Deviation in Relation to Junior High School Students' Well-Being}

The results of a two-way ANOVA comparing school life adjustment and deviant behavior in relation to junior high school students' well-being did not show significant differences, with (deviant behavior * school life adjustment) achieving a $F$ $=.067$ and $p=.935$. Thus we can infer that the combined effect of school life adjustment and deviant behavior does not signifycantly influence well-being. The results of one-way ANOVA for overall well-being showed an $F=744.29$ and $p<.001$, indicating that overall well-being differs according to the level of school life adjustment. The post hoc test results show that students with a good school life adjustment have higher levels of well-being than those with a moderate school life adjustment, and that those with a moderate school life adjustment have higher levels of well-being than those with a poor school life adjustment. The interactions of deviant behavior and familial socioeconomic status and school life adjustment did not significantly influence well-being; thus, we further compared the influence on varying levels of deviant behavior on emotional reaction, self-satisfaction, and physical health. For emotional reaction, $t=8.65$ and $p<.001$, indicating that low deviant behavior generated a higher emotional reaction compared to high deviant behavior. For physical health, $t=7.01$ and $p$ $<.001$, indicating that low deviant behavior generated superior physical health compared to high deviant behavior. For wellbeing, $t=7.93$ and $p<.001$, indicating that low deviant behavior generated higher well-being compared to high deviant behavior, as shown in Table 3.

\section{Discussion}

The results of this study show that familial socioeconomic status, school life adjustment, and deviant behavior influenced the perceived well-being of junior high students, and male students had more positive perceptions compared to female students. Although junior high school students are gradually being independent of their family, their family, school, and personal behavior also affects their perceived well-being. The results show that an interaction exists between family socioeconomic status and school life adjustment. Children that experience a poor family atmosphere, a lack of warmth and family support, school setbacks or difficulties, learning difficulties, or conflicts with classmates or teachers and unlikely to discuss their problems with their parents, resulting in the increased accumulation of negative emotions that are difficult to release and ultimately leading to unhappiness. Junior high school students must face challenges and develop physically and mentally to cope with increased academic stress. In an effort to reduce their reliance on family members, students tend to turn to their peers; they actively seek the recognition and support of their peers and teachers because they need people with whom to share their joys and sorrows.

In addition, students that do not participate in learning activities or exhibit academic ambition have a tendency to display deviant behavior. Maladjustment in school resulting from learning difficulties, teacher-student relationship, or problems with peers increase students' life stress. Then, in an effort to eliminate their anxiety and restlessness, students engage in deviant behavior. Deviant behavior is exhibited to alleviate 
Table 3.

Summary of the t test results for the influence that each dimension of deviant behavior had on well-being.

\begin{tabular}{cccc}
\hline Factor & $t$ & $\eta^{2}$ & Notes \\
\hline Emotional reaction & $8.65^{* * *}$ & .07 & Low $>$ high \\
Self-satisfaction & -12 & - & \\
Physical health & $7.01^{* * *}$ & .04 & Low $>$ high \\
Well-being & $7.93^{* * *}$ & .05 & Low $>$ high \\
\hline
\end{tabular}

Note: ${ }^{* * *} p<.001$.

current jitters or vent feelings anguish, which indicates that the adolescent is unhappy. Thus, school educators should consider students' school life adjustment problems, understand students' family situations, and monitor deviant behavior to increase students' sense of well-being when learning.

\section{Conclusion}

Regarding the well-being of junior high school students, the results showed that differences exist between male and female students for emotional reaction and overall well-being. Male students exhibited comparatively more positive reactions.

Significant differences existed in the combined effect that familial socioeconomic status, deviant behavior, and school life adjustment had on the well-being of junior high school students. Students from families with a high socioeconomic status who were better adjusted to school life exhibited a greater sense of well-being. Students from families with a relatively low socioeconomic status who were poorly adjusted to school life exhibited the highest levels of unhappiness. These findings should be considered by schools and teachers.

Although well-being is a subjective feeling, the factors that influence well-being are external. Familial socioeconomic status, school life adjustment, and deviant behavior all influence well-being and are not necessarily limited to a single factor. Numerous factors can influence well-being simultaneously. For example, a student may have a disharmonious family life and difficulty adjusting to school life, leading to deviant behavior and low morale; thus, the student struggles to be happy.

If learning setbacks or difficulties combined with poor interpersonal interactions result in an inability to receive support and assistance from parents and teachers, a student in this situation would certainly be unhappy. Therefore, if students are found to be exhibiting low moods or they are unhappy, besides inquiring as to the cause, the potential background factors that influence their well-being should be considered, and timely assistance provided.

\section{Study Limitations}

The data used for this study was obtained from one database. Although this database is verified to possess high quality and reliability in Taiwan, readers may consider the data somewhat outdated.

\section{REFERENCES}

Agnew, R., \& White, H. R. (1992). An empirical test of general strain theory. Criminology, 30, 475-499.

doi:10.1111/j.1745-9125.1992.tb01113.x
Andrews, F. M., \& Withey, S. B. (1976). Social indicators of wellbeing: America's perception of life quality. New York: Plenum. doi:10.1007/978-1-4684-2253-5

Brinkman (2002). Culture and subjective well-being. Journal of Economic Issues, 36, 830-834.

Chang (2003). Taiwan education panel survey (TEPS): Junior high school students questionnaire data (2001). Academic Sinica Survey Research Data Archive (SRDA), Taiwan.

Chiang, T. L. (2003). Attachment, social learning and juvenile deviant behavior. Unpublished M.S. Thesis, ChiaYi: Graduate Institute of Sociology of Education of Nanhua University.

Clinard, M. B., \& Meier, R. F. (1992). Sociology of deviant behavior (8th ed.). Fort Worth, TX: Harcourt Brace Jovanovich College Publishers.

Coleman, J. S. (1988). Social capital in the creation of human capital. Supplement to American Journal of Sociology, 94, 95-120. doi: $10.1086 / 228943$

Coleman, J. S. (1990a). Foundations of social theory. Cambridge, MA: Harvard University Press.

Campbell, A. (1976). Subjective measures of well-being. American Psychologist, 31, 117-124. doi:10.1037/0003-066X.31.2.117

Cowley, G., \& Underwood, A. (2002). The science of happiness. Newsweek, 140, 46-48.

Diener, E. (1984). Subjective well-being. Psychological Bulletin, 95, 542-575. doi:10.1037/0033-2909.95.3.542

Diener, E. (2000). Subjective well-being: The science of happiness and a proposal for a national index. American Psychologist, 55, 34-43. doi: 10.1037/0003-066X.55.1.34

Diener, E., Shu, E. M., Smith, H., \& Shao, L. (1995). National differences in reported subjective well-being: Why do they occur? Social Indicators Research, 34, 7-32. doi:10.1007/BF01078966

Epstein, J. L. (1983). The influence of friends on achievement and affective outcomes. In J. L. Epstein, \& N. Karweit (Eds.), Friends in school: Patterns of selection and influence (pp. 177-200). New York: Academic Press.

Freeman, L. J., Templer, D. I., \& Hill, C. (1999). The relationship between adult happiness and self-appraised childhood happiness and events. The Journal of Genetic Psychology, 160, 46-54. doi:10.1080/00221329909595379

Hollingshed, A. B. (1958). Social class and mental illness: A community study. New York: Wiley. doi:10.1037/10645-000

Konu, A. I., Lintonen, T. P., \& Autio, V. J. (2002). Evaluation of wellbeing in schools: A multilevel analysis of general subjective wellbeing. School Effectiveness and School Improvement, 13, 187-200. doi:10.1076/sesi.13.2.187.3432

Ladd, G. W. (1989). Children's social competence and supports: Precursors of early school adjustment? In B. H. Schneider, G. Attili, J. Nadel, \& R. Weissberg (Eds.), Social competence in developmental perspective (pp. 277-299). Boston: Kluwer Academic Publisher. doi:10.1007/978-94-009-2442-0_17

Lazarus, R. S. (1976). Patterns of adjustment. New York: McGrawHill.

Leung, J. P., \& Leung, K. (1992). Life satisfaction, self-concept and relationship with parents in adolescence. Journal of Youth and Adolescence, 21, 653-665. doi:10.1007/BF01538737

Lewis, M. (1995). Shame: The exposed self. New York: Free Press.

Li, S. C. (2002). The study of the relationships between adolescent's family support and well-being-the example of the junior high school students in Taichung. Unpublished M.S. Thesis, Taichung: Providence University.

Lin, N. (2001). Social capital: A theory of social structure and action. New York: Cambridge. doi:10.1017/CBO9780511815447

Lin, S. H., \& Huang, Y. C. (2008). The relationship between school factors and subjective well-being for high school students. The Archive of Guidance \& Counseling, 30, 83-106.

Lin, S. L. (2000). The relationship among self-concept, study behaviors and school adjustment of returned probationary students in vocational senior high school. Unpublished M.S. Thesis, Taiwan: National Taiwan Normal University, Taiwan.

Liu, F. F. (2008). The Relationship among life experience, school life 
adjustment and well-being on junior high school students. Unpublished M.S. Thesis, ChangHua: Professional Development in Education of DA-YEH University.

Liu, J. C. (2003). The relevant research of teenager's family attachment, school experience, and deviance-Nantou county as an example. Unpublished M.S. Thesis, ChiaYi: Graduate Institute of Sociology of Education of Nanhua University.

Lyubomirsky, S., King, L., \& Diener, E. (2005). The benefits of frequent positive affect: Does happiness lead to success? Psychological Bulletin, 131, 803-855. doi:10.1037/0033-2909.131.6.803

McCulloch, B. J. (1992). Gender and race: An interaction affecting the replicability of well-being across groups. Women \& Health, 19, 6589. doi:10.1300/J013v19n04_05

Murray, C. (2002). Supportive teacher-student relationships: Promoting the social and emotional health of early adolescents with high incidence disabilities. Childhood Education, 78, 285-290. doi:10.1080/00094056.2002.10522743

Noll, R. B., Vannatta, K., Koontz, K., Kalinyak, K. A., Bukowski, W. M., \& Davies, W. H. (1996). Peer relationships and emotional wellbeing of children with sickle cell disease. Child Development, 67, 423-436.

Ollendick, T.H., Weist, M.D., Borden, C., \& Greene, R.W. (1992). Sociometric status and academic, behavioral, and psychological adjustment: A five-year longitudinal study. Journal of Consulting and Clinical Psychology, 60, 80-87.

doi:10.1037/0022-006X.60.1.80

Paula, F., \& Andrew, J. C. (2007). Family instability and child well- being. American Sociological Review, 72, 181-204. doi:10.1177/000312240707200203

Seligman, M. E., \& Csikszentmihalyi, M. (2000). Positive psychology: An introduction. American Psychologist, 55, 5-14. doi:10.1037/0003-066X.55.1.5

Shyu, M. L. (2007). Correlational study of social relationships, mental health, deviant behaviors, and happiness among young adolescents. New Taipei Journal of Nursing, 9, 23-34.

Wentzel, K. R. (1996). Social goals and social relationships as motivators of school adjustment. In J. Juvonen, \& K. R. Wentzel (Eds.), Social motivation: Understanding children's school adjustment. Boston: Cambridge University Press.

doi:10.1017/CBO9780511571190.012

Werum, R. E. (2000). The ethnic dimension of social capital: How parental networks sharp track placement in Germany. Annual Conference of the American Educational Research Association. New Orleans, LA.

Wu, C. J., \& Chang, T. S. (2003). The comparison between elementary students reared by grandparents and students reared by parents regarding to school life adaptation. Journal of National Hualien Teachers College, 16, 109-134.

Wu, W. D. (1978). Bad behavior counseling strategies. Testing and Counseling, 7, 469-474.

Peng, L. Y. (2011). Importing welling-being from Bhutan to Taiwan. Globalviews Magazine, 296. URL (last checked 14 January 2013). http://www.gvm.com.tw/Boardcontent_17384.html 